Revision 12-22-2014

\title{
Phase analysis and determination of local charge carrier concentration in eutectic $\mathrm{Mg}_{2} \mathrm{Si}-\mathrm{Si}$ alloys
}

\author{
E.M. Levin ${ }^{1,2 *}$, R. Hanus ${ }^{1}$, J. Cui ${ }^{1,3}$, Q. Xing ${ }^{1}$, T. Riedermann ${ }^{1}$, \\ T. Lograsso ${ }^{1,4}$, and K. Schmidt-Rohr ${ }^{1,3}$
}

${ }^{1}$ Division of Materials Sciences and Engineering, US DOE Ames Laboratory, Ames, IA 5011, USA ${ }^{2}$ Department of Physics and Astronomy, Iowa State University, Ames, IA 50011, USA

${ }^{3}$ Department of Chemistry, Iowa State University, Ames, IA 50011, USA

${ }^{4}$ Department of Materials Science and Engineering, Iowa State University, Ames, IA 50011, USA

Submitted to Materials Chemistry and Physics

\begin{abstract}
Multiphase materials attract attention due to possible combination of various properties attributed to each phase. The phase diagram of $\mathrm{Mg}$-Si system shows that solidification of a melt containing about 45 and 55 at.\% of $\mathrm{Mg}$ and $\mathrm{Si}$ should result in formation of $\mathrm{Mg}_{2} \mathrm{Si}$ and $\mathrm{Si}$. Two alloys, $\mathrm{Mg}_{45} \mathrm{Si}_{55}$ and $\mathrm{Mg}_{46} \mathrm{Si}_{54}+0.5$ wt.\% Cu have been synthesized and studied using XRD, SEM, and ${ }^{29} \mathrm{Si}$ NMR at $300 \mathrm{~K}$, and the Seebeck effect, electrical resistivity, and thermal conductivity in the temperature range of $300-750 \mathrm{~K}$ have been measured. ${ }^{29} \mathrm{Si}$ NMR detects two distinct signals, at -177 and $-80 \mathrm{ppm}$, in both materials, which are attributed to $\mathrm{Mg}_{2} \mathrm{Si}$ and $\mathrm{Si}$ phases, respectively. Both phases are slightly nonstoichiometric and doped with $\mathrm{Mg}$. Two phases also are found by XRD and electron microscopy. ${ }^{29} \mathrm{Si}$ NMR spin-lattice relaxation measurements in $\mathrm{Mg}_{2} \mathrm{Si}$ and $\mathrm{Si}$ phases show at least two components, short and long, which can be attributed to different local carrier concentrations, high and low, respectively, reflecting a local electronic inhomogeneity in each phase. The carrier concentration range between $0.6 \times 10^{19}$ and $9 \times 10^{19} \mathrm{~cm}^{-3}$. The Seebeck coefficient in both alloys is mostly determined by the Si phase, while the thermal conductivity is limited by the $\mathrm{Mg}_{2} \mathrm{Si}$ phase with a lower value than that of the Si phase. By utilizing all characterization tools, we show how various experimental methods can be used as complementary methods to better understand the individual and combined properties of multiphase alloys.
\end{abstract}

PACS: 61.10.-i; 61.66.Fn; 68.37.Hk; 76.60.-k; 72.20.Pa

Keywords: crystal structure; electron microscopy; nuclear magnetic resonance; thermoelectric effects; thermal properties.

a) Author to whom correspondence should be addressed. E-mail: levin@iastate.edu 


\section{Introduction}

Multi-phase materials may have attractive electronic, magnetic, thermal and other properties due to (i) specific contributions from each phase and (ii) material microstructure. Such materials can be used as a base to design novel materials via control of phase volumes and/or microstructures through varied composition or solidification process. However, this requires a better understanding of the properties of all phases and control of the microstructure features in the multi-phase material. Electronic properties of multi-phase materials, particularly electrical resistivity and thermopower, depend mostly on the composition of the solidified phases and microstructure of the alloy. Si-containing materials are particularly interesting because $\mathrm{Si}$ is a semiconductor with a large energy-band gap, $1.12 \mathrm{eV}$, low carrier concentration, and high electrical resistivity at $300 \mathrm{~K}$, but doping with various elements strongly affect these parameters resulting in $n$ - (when As or $\mathrm{P}$ are used as dopant) or $p$-type (B, In) conductivity [1].

It is worth noting here that one of the advantages of multi-phase Si-containing materials is the possibility to enhance energy filtering and thermopower $[2,3]$ due potential barriers around the grains of different phases similar to that observed for highly boron-doped $p$-type nanocrystalline $\mathrm{Si}$ [4]. $\mathrm{Mg}_{2} \mathrm{Si}$ is one of the most interesting silicides; it is used as an additive to aluminum alloys, as a negative electrode material for lithium-ion batteries, and in photovoltaic applications $[5] . \mathrm{Mg}_{2} \mathrm{Si}$ also is one of the well-known base compounds for thermoelectric materials where doping (alloying) with various elements may improve thermoelectric properties [6-10].

There are several parameters which can affect physical properties of complex materials, particularly those containing at least two phases; among them can be (i) the composition of each phase, (ii) the crystal structure, and (iii) the microstructure. Properties which can be affected include the electrical resistivity, thermal conductivity, and also the Seebeck coefficient, one of the 
key parameters of thermoelectric materials. Tuning these parameters, through iterated cycles of modification and analysis, may form conditions for the chemical engineering and design of materials with desired properties. Note that all these parameters depend on the free (mobile) charge carrier concentration. Hence, various differential and integral experimental methods for measuring this quantity are needed to better understand such materials.

In this paper we present experimental data of a comprehensive study of two materials, $\mathrm{Mg}_{45} \mathrm{Si}_{55}$ and $\mathrm{Mg}_{46} \mathrm{Si}_{54}+0.5 \mathrm{wt} \% \mathrm{Cu}$, using X-ray diffraction (XRD), scanning electron

microscopy (SEM), ${ }^{29}$ Si nuclear magnetic resonance (NMR), Seebeck coefficient (thermopower), electrical resistivity, and thermal diffusivity. According to Ref. 11, the phase diagram of the $\mathrm{Mg}-\mathrm{Si}$ system shows an eutectic point with a temperature of solidification of $1220 \mathrm{~K}$ for 45 at. $\% \mathrm{Mg}$ and 55 at.\% Si. It is expected that at least two different phases are formed during solidification of a liquid of the nominal composition. This is the motivation to study such alloys using several different methods, integral and local, to characterize solidified $\mathrm{Mg}_{45} \mathrm{Si}_{55}$. In addition, other elements like $\mathrm{Cu}$ may affect local and long-range properties of Mg-Si based materials. By utilizing the above characterization tools, we show how various experimental methods can be used as complementary methods to better understand the individual and combined properties of multiphase alloys.

\section{Experimental details}

\subsection{Materials synthesis and sample preparation}

Starting materials, 99.5 wt.\% Mg and 99.999 wt.\% Si purity, were pre-cast via bottom-pour chill-cast in an induction furnace. A small amount of $\mathrm{Cu}$, about $0.5 \mathrm{wt} . \%$, which is about 2 atomic (at.) \%, was added for some alloys. The materials were placed into a graphite crucible with an 
interior boron-nitride coating and heated to $573 \mathrm{~K}$ under a vacuum of about $3.8 \times 10^{-3} \mathrm{~Pa}$ to degas the material/crucible assembly. Then the furnace was backfilled with high purity argon gas to a pressure of $1.7 \times 10^{4} \mathrm{~Pa}$. The materials were heated to $1323 \mathrm{~K}$ for $10 \mathrm{~min}$, subsequently heated to $1348 \mathrm{~K}$, and immediately poured into a graphite crucible in a water-chilled copper mold. A contiguous but porous ingot of $250-290 \mathrm{~mm}$ length and $18 \mathrm{~mm}$ diameter was obtained. The material net loss is about $2 \mathrm{wt} . \%$ and was compensated by adding excess magnesium in the starting materials. Approximately $90 \mathrm{~g}$ of as-cast alloy was crushed with a Retsch BB51 jaw crusher into 1$3 \mathrm{~mm}$ particles and subsequently sealed in a tantalum crucible with a $25.4 \mathrm{~mm}$ outer diameter, 200 $\mathrm{mm}$ length, and a $0.76 \mathrm{~mm}$ wall thickness under a helium gas of $2.4 \times 10^{4} \mathrm{~Pa}$ pressure. Directional solidification was conducted in Bridgman furnace.

The crucible was heated under vacuum to $1523 \mathrm{~K}$ at a rate of $873 \mathrm{~K} / \mathrm{h}$, kept at the temperature for $1 \mathrm{~h}$, and then withdrawn from the furnace at $50 \mathrm{~mm} / \mathrm{h}$. No weight loss occurred during the solidification process. Inspection of the crucible interior confirmed complete melting of the as-cast alloy. Specimens for thermoelectric measurements were cut from the ingots with an electrical discharge machine (EDM).

\subsection{X-ray diffraction (XRD), scanning electron microscopy (SEM), and energy dispersive} spectroscopy (EDS)

XRD patterns were obtained on ground powders at room temperature using a Rigaku Ultima IV with $\mathrm{Cu}-\mathrm{K}_{\alpha}$ radiation $(\lambda=0.154 \mathrm{~nm})$. Multi-phase Rietveld refinements were conducted in the program X'Pert Highscore Plus for phase analysis, and determination of the weight percent and crystal structure of each phase. The crystallographic data used in these refinements for the $\mathrm{Mg}_{2} \mathrm{Si}$ (Fm-3m) and Si (Fd-3m) phases were obtained from Pearson's Crystal Data [12]. Heat treatment 
was done under flowing He in an OTF-1200x vacuum tube furnace. The crystal structure of each phase was determined and the lattice parameters of each phase are in good agreement with values found in literature [13-15]. The relative weight percent of each phase was determined from the Rietveld refinements using the matrix flushing method [16]. The microstructure was examined in a JEOL JSM-5910LV scanning electron microscope (SEM).

\subsection{Nuclear Magnetic Resonance (NMR)}

Solid-state ${ }^{29}$ Si NMR experiments were run on a Bruker Biospin (Billerica, MA) DSX-400 spectrometer (magnetic field of 9.39 T) at 79.49 MHz using a 4-mm probe with magic angle spinning (MAS) at $10 \mathrm{kHz}, \pi / 2$ saturation pulse length $6 \mathrm{~s}$, and recovery times ranging from 1 to 1400 s. Signals were detected after a Hahn echo pulse sequence $(\pi / 2-\tau-\pi-\tau$-acquisition $)$ with $\pi / 2$ pulse length of $4 \mathrm{~s}, \pi$ pulse length of $8 \mathrm{~s}$, and $\tau$ of $7 \mathrm{~s}$ with a recycle delay of $0.1 \mathrm{~s}$. The number of scans varied between 32 and 4096 for different delay time; measuring times were between 32 and $49 \mathrm{~h}$ for one sample. ${ }^{29} \mathrm{Si}$ NMR chemical shifts were referenced to tetramethylsilane, $\mathrm{Si}\left(\mathrm{CH}_{3}\right)_{4}$, at $0 \mathrm{ppm}$. The spin-lattice relaxation time, $T_{1}$, was obtained by fitting the dependence of normalized integral vs. the saturation-recovery time.

\subsection{Seebeck coefficient, electrical resistivity, and thermal conductivity}

Measurements of the Seebeck coefficient (thermopower) and electrical resistivity were performed using an LSR-3 measuring system (Linseis Inc.) in a helium environment in the temperature range from 300 to $750 \mathrm{~K}$. The Seebeck coefficient and electrical resistivity were measured simultaneously on the same sample using a four-probe method; the temperature difference for thermopower measurements was between 8 and $9 \mathrm{~K}$ in the entire temperature range 
with an uncertainty of $\leq 0.1 \mathrm{~K}$. The Seebeck coefficient was measured relative to the Pt legs of a $\mathrm{Pt}-(\mathrm{Pt}+\mathrm{Rh})$ thermocouple and then the absolute Seebeck coefficient was calculated [17]. The uncertainties for the Seebeck coefficient and electrical resistivity measurements were $\leq 5 \%$ and $3 \%$, respectively. More experimental details for electron transport measurements can be found in Ref. 17. The same two disc samples were also used for thermal diffusivity (conductivity) measurements using the flash thermal diffusivity method. The sample was coated with a layer of graphite. The thermal diffusivity, $\lambda$, and heat capacity, $c_{\mathrm{p}}$, were measured with an XFA-500 measuring system (Linseis Inc.) in a helium environment; the uncertainty of measurements is $\sim 6 \%$ [17]. The mass density of the samples was measured at $300 \mathrm{~K}$ by the Archimedes method using an AT261 Delta Range, Mettler Toledo.

\section{Experimental results and discussion}

\subsection{X-ray diffraction}

The XRD pattern for as-solidified $\mathrm{Mg}_{45} \mathrm{Si}_{55}$ in Figure 1(a) shows that the alloy contains two major phases, $\mathrm{Mg}_{2} \mathrm{Si}$ and $\mathrm{Si}$. The mass percent and crystal structure of each phase were determined via multi-phase Rietveld refinement (see Table 1) and the lattice parameters of each phase are in good agreement with values found in literature [1,13-15]. Samples extracted from different locations on the ingot have similar patterns indicating the alloy composition is uniform throughout the cast ingot. For example, Fig.1(a) shows the XRD pattern for $\mathrm{Mg}_{45} \mathrm{Si}_{55}$. Figure 1(b) shows the XRD pattern for the same $\mathrm{Mg}_{45} \mathrm{Si}_{55}$ sample after a heat treatment at $780 \mathrm{~K}$ for $2 \mathrm{~h}$. The heat treatment results in the appearance of a small amount of $\mathrm{MgO}$; this can explain an increase of the Si phase by $\sim 7 \%$ via a reduction of the $\mathrm{Mg}_{2} \mathrm{Si}$ phase. In addition, the lattice parameters of $\mathrm{Mg}_{2} \mathrm{Si}$ after heat treatment are slightly larger than before (Table 1), suggesting that $\mathrm{Mg}_{2} \mathrm{Si}$ phase has a 
higher Si content in the as solidified, which precipitates as elemental Si after heat treatment. Note that oxidation of $\mathrm{Mg}$ takes place even though the heat treatment was conducted under flowing He.

The XRD pattern of $\mathrm{Mg}_{46} \mathrm{Si}_{54}+0.5$ wt.\% Cu in Figure 2(a) shows that in addition to $\mathrm{Mg}_{2} \mathrm{Si}$ and Si phases, a third phase of $\mathrm{Cu}$ was present in small concentration with a primary peak at $\sim 43^{\circ}$. Because of the low intensity of the $\mathrm{Cu}$ peaks, it was not possible to conduct accurate refinements on this phase. However, by examining the lattice parameters of the $\mathrm{Mg}_{2} \mathrm{Si}$ and $\mathrm{Si}$ phases in the assolidified $\mathrm{Mg}_{45} \mathrm{Si}_{55}$ and $\mathrm{Mg}_{46} \mathrm{Si}_{54}+0.5$ wt.\% $\mathrm{Cu}$ samples (Table 1), it is clear that some $\mathrm{Cu}$ is present in these lattices. Heat treatment of $\mathrm{Mg}_{46} \mathrm{Si}_{54}+0.5 \mathrm{wt} . \% \mathrm{Cu}$, in contrast to $\mathrm{Mg}_{45} \mathrm{Si}_{55}$, resulted in a decrease in the concentration of the Si phase by $\sim 5 \%$ [Figure 2(b)]. According to ASM International Phase Diagrams Database [11], $\mathrm{Cu}$ and $\mathrm{Si}$ may form various compounds, e.g., binary $\mathrm{Cu}-\mathrm{Si}$ or ternary $\mathrm{Mg}-\mathrm{Cu}-\mathrm{Si}$, which, however, cannot be distinguished by $\mathrm{XRD}$, but may result in a decrease of the Si phase and an increase of the $\mathrm{Mg}_{2} \mathrm{Si}$ phase due to heat treatment. Hence, both materials studied contain elemental Si and binary $\mathrm{Mg}_{2} \mathrm{Si}$ compound forming multiphase systems.

\subsection{Scanning electron microscopy}

The directionally solidified alloys show the eutectic $\mathrm{Mg}_{2} \mathrm{Si}-\mathrm{Si}$ structure with $\mathrm{Mg}_{2} \mathrm{Si}$ matrix and discontinuous Si network (see Figure 3, where images indicate a refinement close to the surface). Si phase usually shows irregular morphology, but sometimes has fishbone structure. These features are typical for anomalous or eutectic solidification [18], demonstrating that the $\mathrm{Mg}_{2} \mathrm{Si}$-Si eutectic solidification is anomalous. Images in longitude view (not shown) present almost identical microstructural features, indicating that there is no directional growth along the cooling direction for either phase under the current solidification conditions. 
With the exception of the regions adjacent to the Ta crucible wall, the microstructure is relatively homogeneous across a transverse view. However, the ingot top surface shows finer Si phases (Figures 3a,b) than the bottom (Figures 3c,d). These differences in microstructural length scales result from interactions with the Ta crucible wall altering the heat transfer conditions at the start of solidification where cooling rates may be slower. Si phase at the ingot bottom has spacing ranging 5-25 $\mu \mathrm{m}$ and width ranging 1-10 $\mu \mathrm{m}$, whereas Si phase at the ingot top has spacing ranging 2-15 $\mu \mathrm{m}$ and width ranging 1-6 $\mu \mathrm{m}$. The spacing and width measurements were conducted from SEM images. The addition of $0.5 \mathrm{wt} . \% \mathrm{Cu}$ does not change the solidification behavior nor the microstructure length scale (Figure 4). Pure $\mathrm{Cu}$ precipitates at or close to $\mathrm{Mg}_{2} \mathrm{Si} / \mathrm{Si}$ interfaces were observed by XRD as well as SEM.

\section{3. ${ }^{29}$ Si NMR spectra, spin-lattice relaxation, and carrier concentration}

Figure 5 shows ${ }^{29} \mathrm{Si}$ NMR spectra of two different $\mathrm{Mg}_{45} \mathrm{Si}_{55}$ samples (Fig. 5(a,b)] and of $\mathrm{Mg}_{46} \mathrm{Si}_{54}+0.5$ wt.\% Cu [Fig. 5(c)]. Each spectrum exhibits two peaks, at -177 and $-80 \mathrm{ppm}$. Based on literature data for ${ }^{29} \mathrm{Si} \mathrm{NMR}$ of $\mathrm{Mg}_{2} \mathrm{Si}$ [19-18] and $\mathrm{Si}$ [20-19], these peaks can be attributed to $\mathrm{Mg}_{2} \mathrm{Si}$ and Si phases, respectively. The ratio of the intensities of these peaks reflects the relative amount of $\mathrm{Mg}_{2} \mathrm{Si}$ and $\mathrm{Si}$ phases. The similar spectral patterns with and without $\mathrm{Cu}$ confirm that $\mathrm{Cu}$ addition does not significantly change the solidification of the alloy.

The charge carrier concentration in semiconductors is one of the most important parameters affecting electronic and thermal transport. For determination of the carrier concentration, the Hall effect is typically used [21-20]. While this method, which shows an integral signal, is reliable for single-phase materials, it may show misleading data when used for the determination of charge carrier concentration in electronically inhomogeneous materials; a contribution from a second 
phase present in the matrix of the material even in small quantity can significantly affect the Hall effect signal [22-21]. In contrast, the NMR spectrum can resolve signals from phases with different Knight shifts of the NMR frequency due to different carrier concentrations [23-22,24-23]. Both the ${ }^{29} \mathrm{Si}$ Knight shift and the spin-lattice $\left(T_{1}\right)$ relaxation are due to hyperfine coupling between the nuclear spins and free charge carriers; as a result, an increased Knight shift correlates characteristically with decreased $T_{1}$ relaxation time [23-22]. This is demonstrated for $\mathrm{Mg}_{45} \mathrm{Si}_{55}$ in Fig. 6, where components with short $T_{1}$, selected by a short saturation-recovery time of $10 \mathrm{~s}$, show Knight-shifted signals distinct from the sharp peaks associated with the longest $T_{1}$, selected by a 30-s $T_{1}$ filter before detection.

Figure 7 shows ${ }^{29} \mathrm{Si}$ NMR spin-lattice relaxation data of $\mathrm{Mg}_{45} \mathrm{Si}_{55}$ [Fig. 7(a)] and $\mathrm{Mg}_{46} \mathrm{Si}_{54}+0.5$ wt. $\% \mathrm{Cu}$ [Fig. 7(b)]. For both materials, relaxation can be fit by at least two components with different spin-lattice relaxation times, $T_{1}$, similarly as observed for complex tellurides [23-22,24-23]. Depending on the sample and heat treatment, for the $\mathrm{Mg}_{2} \mathrm{Si}$ phase the shorter $T_{1}$ varies between 12 and $16 \mathrm{~s}$, and the longer $T_{1}$ between 100 and $180 \mathrm{~s}$. For the Si phase, the shorter $T_{1}$ varies between 15 and $24 \mathrm{~s}$, and the longer $T_{1}$ between 90 and $300 \mathrm{~s}$. In electrically conductive materials, spin-lattice relaxation is mostly due to interaction of nuclei with conduction electrons and the rate $1 / T_{1}$ is approximately proportional to the carrier concentration. Hence, the different $T_{1}$ values can be attributed to "high" and "low" carrier concentrations in each phase, i.e., both $\mathrm{Mg}_{2} \mathrm{Si}$ and Si phases contain regions of different local carrier concentration and are electronically inhomogeneous. The $T_{1}$-selective spectra of Figure 6 confirm this conclusion. The observed inhomogeneity can be explained by inhomogeneous doping of $\mathrm{Si}$, likely with $\mathrm{Mg}$, and variation of the $\mathrm{Mg}$ :Si ratio in $\mathrm{Mg}_{2} \mathrm{Si}$, which requires us to place " $\mathrm{Mg}_{2} \mathrm{Si}$ " and "Si" in quotation marks, indicating that in reality these phases are not pure and homogeneous. 
Calibration of spin-lattice relaxation times in complex tellurides has enabled us to convert $T_{1}$ to carrier concentration [24-23]. Similarly, ${ }^{29} \mathrm{Si}$ NMR $T_{1}$ measurements were used earlier by Shulman and Wyluda [25-24] and confirmed by Abragam [26-25] (see also Brown and Holcomb [27-26]) to obtained carrier concentration in $n$ - and $p$-type Si. Using the calibration curve from Refs. 25-24,26-25, we have estimated the mobile carrier concentration in both our samples; the results are shown in Table 2. The carrier concentration in the " $\mathrm{Mg}_{2} \mathrm{Si}$ " phase present in $\mathrm{Mg}_{45} \mathrm{Si}_{55}$ varies between $\sim 7 \times 10^{18}$ and $\sim 9 \times 10^{19} \mathrm{~cm}^{-3}$, while that in the "Si" phase ranges between $\sim 10^{19}$ and $\sim 7 \times 10^{19} \mathrm{~cm}^{-3}$. Note that the carrier concentration in undoped $\mathrm{Mg}_{2} \mathrm{Si}$ is much lower, $2.9 \times 10^{17} \mathrm{~cm}^{-3}$ or $8.4 \times 10^{18} \mathrm{~cm}^{-3}$ according to Ref. 9 or Ref. 7, respectively.

The carrier concentration in the " $\mathrm{Mg}_{2} \mathrm{Si}$ " phase present in $\mathrm{Mg}_{46} \mathrm{Si}_{54}+0.5$ wt. $\% \mathrm{Cu}$ varies between $\sim 6 \times 10^{18}$ and $\sim 7 \times 10^{19} \mathrm{~cm}^{-3}$, while that in the "Si" phase is between $\sim 4 \times 10^{18}$ and $4 \times 10^{19}$ $\mathrm{cm}^{-3}$. Hence, doping with $\mathrm{Cu}$ does not significantly change the carrier concentration in " $\mathrm{Mg}_{2} \mathrm{Si}^{\prime}$, while the effect in the "Si" phase is larger showing that $\mathrm{Cu}$ likely is a dopant in Si. Note that the intrinsic carrier concentration in $\mathrm{Si}$ at $300 \mathrm{~K}$ is $\sim 10^{14} \mathrm{~cm}^{-3}$ [1], which is much lower than that obtained for the "Si" phase from ${ }^{29} \mathrm{Si}$ NMR and indicates the effect of doping.

\subsection{Phase analysis in multiphase materials: $N M R$ vs. XRD and electron microscopy}

Now we compare the data for $\mathrm{Mg}_{45} \mathrm{Si}_{55}$ and $\mathrm{Mg}_{46} \mathrm{Si}_{54}+0.5$ wt.\% $\mathrm{Cu}$ obtained by XRD and ${ }^{29} \mathrm{Si}$ NMR. From the intensities of the peaks in the quantitative ${ }^{29} \mathrm{Si}$ NMR spectra, the amounts of the Si-rich phase and $\mathrm{Mg}_{2} \mathrm{Si}$-rich phase can be determined. For the Si-rich phase, the ${ }^{29} \mathrm{Si}$ NMR peakintegral fraction is denoted as $I_{S i}$ and the mass fraction as $f_{S i}$, while for the $\mathrm{Mg}_{2} \mathrm{Si}$-rich phase, $I_{M_{g_{2} S i}}=1-I_{S i}$ and $f_{M_{2} S i}=1-f_{S i}$. The mass ratio of $\mathrm{Si}$ in the Si-rich phase versus in the $\mathrm{Mg}_{2} \mathrm{Si}$ 
phase, $f_{S i}:\left[\left(1-f_{S i}\right) / 2.73\right]$ is equal to the ratio of the integrals of the corresponding ${ }^{29} \mathrm{Si}$ NMR peaks as

$$
\frac{2.73 \times f_{S i}}{1-f_{S i}}=\frac{I_{S i}}{I_{M g_{2} S i}}
$$

This can be solved for the mass fraction of the Si-rich phase as

$$
f_{S i}=\frac{I_{S i}}{I_{S i}+2.73 \times I_{M g_{2} S i}}
$$

The calculated fractions of " $\mathrm{Mg}_{2} \mathrm{Si}$ " and "Si" in $\mathrm{Mg}_{45} \mathrm{Si}_{55}$, (samples \#1 and \#2), and in $\mathrm{Mg}_{46} \mathrm{Si}_{54}+0.5$ wt. $\% \mathrm{Cu}$ are shown in Table 1 . The values for the first two samples are close to those obtained from XRD data, while that for the last one is smaller, which can be explained by the presence of additional phases, i.e., $\mathrm{Cu}$ and $\mathrm{MgO}$ in small quantities (see details in Section $\mathrm{A}$ ).

Hence, both NMR and XRD can be used to estimate the Si content in Mg-Si, but in addition, XRD can be used to calculate lattice parameters. On the other hand, ${ }^{29} \mathrm{Si}$ NMR allows us to determine the carrier concentrations and their distribution via spin-lattice relaxation measurements using both signals attributed to regions with different carrier concentrations in both $\mathrm{Mg}_{2} \mathrm{Si}$ and $\mathrm{Si}$ phases (Table 2). Electronic inhomogeneity detected by ${ }^{29} \mathrm{Si}$ NMR may have an effect on electronic and thermal properties of complex silicides similarly to what we observed for complex tellurides [23-22,24-23]. Both methods can be efficiently used for phase analysis of multiphase materials. Note that the Hall effect does not allow us to determine the carrier concentration in each phase in multiphase materials and cannot detect electronic inhomogeneity. In addition to our data for tellurides reported in Refs. 23-22,24-23, our data for silicides shown here demonstrate that solid state NMR is a unique method allowing determination of carrier concentration in complex materials. Our data also show that XRD and NMR are complimentary methods allowing us to obtain valuable information about physics and chemistry of complex materials. 
Backscattered electron images of Mg-Si alloys (Figures 3 and 4) also show the presence of at least two phases, $\mathrm{Mg}_{2} \mathrm{Si}$ and Si. Electron microscopy in addition to XRD and NMR demonstrates that on a large scale the alloys are relatively homogeneous. However, XRD cannot determine if each phase in Mg-Si materials is homogeneous or not. The accuracy of composition determination by electron microprobe analysis using wavelength-dispersive spectroscopy typically about \pm 0.5 $2 \%$ for elements above 1 mass.\% [28]. Neither technique can be used for the determination of carrier concentration. In contrast, ${ }^{29} \mathrm{Si}$ NMR is capable of this, which makes it very useful for studying multiphase materials.

\subsection{Seebeck coefficient and electrical resistivity}

It is well-known that $\mathrm{Mg}_{2} \mathrm{Si}$ is used as a base for thermoelectric materials (see the Introduction). Hence, it is of interest to measure thermoelectric properties of $\mathrm{Mg}_{45} \mathrm{Si}_{55}$ and $\mathrm{Mg}_{46} \mathrm{Si}_{54}+0.5$ wt. $\% \mathrm{Cu}$ and compare them with those for $\mathrm{Mg}_{2} \mathrm{Si}$ reported in different publications. Figure 8 shows temperature dependencies of the Seebeck coefficient and electrical resistivity of $\mathrm{Mg}_{45} \mathrm{Si}_{55}$ for the first [Fig. 8(a)] and second run [Fig. 8(b)]. At $300 \mathrm{~K}$, the Seebeck coefficient is positive and large, $+270 \mathrm{VK}^{-1}$, showing predominant $p$-type conductivity, and decreases when temperature rises. The electrical resistivity is large, $300 \mathrm{~m}$, and does not significantly change with temperature. At $\sim 620 \mathrm{~K}$, the Seebeck coefficient shows a peak; a similar feature also is observed for the electrical resistivity. The second run shows that the Seebeck coefficient at $300 \mathrm{~K}$ is slightly larger, $+310 \mathrm{VK}^{-1}$, and decreases with temperature [Figs. 8(b)]; the electrical resistivity also does not change significantly, but no peaks are observed for both parameters. Because alloys studied here contain various phases, it is difficult to explain changes in the Seebeck coefficient and electrical resistivity observed for the second run. However, we have suggested that they can be 
attributed to the change in (i) temperature-induced activations of the charge carriers in phases present in alloys, and/or (ii) carrier mobility affected by phase boundaries.

The behavior of the Seebeck coefficient and electrical resistivity of $\mathrm{Mg}_{46} \mathrm{Si}_{54}+0.5 \mathrm{wt} . \% \mathrm{Cu}$ [Figs. 9(a) and (b)] are very similar to those of $\mathrm{Mg}_{45} \mathrm{Si}_{55}$. Note that both the Seebeck coefficient and electrical resistivity for $\mathrm{Mg}_{45} \mathrm{Si}_{55}$ and $\mathrm{Mg}_{46} \mathrm{Si}_{54}+0.5 \mathrm{wt} . \% \mathrm{Cu}$ alloys during the third run are similar to those observed for the second run. One of the most important questions is why $\mathrm{Mg}_{45} \mathrm{Si}_{55}$ and $\mathrm{Mg}_{46} \mathrm{Si}_{54}+0.5$ wt. $\% \mathrm{Cu}$ alloys show a large positive Seebeck coefficient instead of a negative one, reported for undoped $\mathrm{Mg}_{2} \mathrm{Si}$ [6-10], and much larger electrical resistivity.

It is well-known that the Seebeck coefficient, S, generally increases when the carrier concentration, $p$ - (hole) or $n$ - (electron) type conductivity, decreases and within a model of parabolic band with energy independent carrier scattering $S \sim 1 / p^{2 / 3}$ [29]. Electron microscopy (Figures 3 and 4) shows that samples studied contain two phases, Si and $\mathrm{Mg}_{2} \mathrm{Si}$. Hence, a large positive Seebeck coefficient shows the presence of a large positive contribution, which overcomes a negative one from $\mathrm{Mg}_{2} \mathrm{Si}$ and can be attributed to $\mathrm{Si}$ doped with $\mathrm{Mg}$. Finally, in spite of the large Seebeck coefficient of $\mathrm{Mg}_{45} \mathrm{Si}_{55}$ and $\mathrm{Mg}_{46} \mathrm{Si}_{54}+0.5 \mathrm{wt} . \% \mathrm{Cu}$ materials, their power factor at $300 \mathrm{~K}$ is very low, 0.2 and $0.4 \mathrm{Wcm}^{-1} \mathrm{~K}^{-2}$, respectively. At $700 \mathrm{~K}$, the power factor is even smaller, about $0.04 \mathrm{Wcm}^{-1} \mathrm{~K}^{-2}$, because the Seebeck coefficient decreases significantly with temperature. Note that power factor estimated for undoped $\mathrm{Mg}_{2} \mathrm{Si}$ at $300 \mathrm{~K}$ is much larger, about 4 [6] or $18 \mathrm{Wcm}^{-}$ ${ }^{1} \mathrm{~K}^{-2}[7]$.

\subsection{Thermal conductivity}

Temperature dependencies of the thermal diffusivity are shown in Figure 10. At $300 \mathrm{~K}$, the thermal diffusivity of $\mathrm{Mg}_{45} \mathrm{Si}_{55}$ and $\mathrm{Mg}_{46} \mathrm{Si}_{54}+0.5 \mathrm{wt} . \% \mathrm{Cu}$ is 0.105 and $0.095 \mathrm{~cm}^{2} \mathrm{~s}^{-1}$, 
respectively, which is much smaller than that of $\mathrm{Si}, \lambda=0.86 \mathrm{~cm}^{2} \mathrm{~s}^{-1}$ [30], but larger than $\mathrm{Mg}_{2} \mathrm{Si}, \lambda$ $=0.06 \mathrm{~cm}^{2} \mathrm{~s}^{-1}$, estimated from Refs. $6,7,31,32$, which can be attributed to the interpolation between the contributions from $\mathrm{Mg}_{2} \mathrm{Si}$ and $\mathrm{Si}$ phases formed in $\mathrm{Mg}-\mathrm{Si}$ alloys.

The thermal diffusivity of both samples decreases with temperature, which is typical for solids when lattice thermal conductivity (via phonon propagation) prevails [33]. The total thermal conductivity, $\kappa_{\text {tot }}$, was calculated for $300 \mathrm{~K}$ via the equation $\kappa_{\mathrm{tot}}=\lambda c_{\mathrm{p}} d$, where $d$ is the mass density; using experimental values for all these parameters (see Table 3 , where literature values of $d$ and $c_{\mathrm{p}}$ for $\mathrm{Mg}_{2} \mathrm{Si}$ and $\mathrm{Si}[1,34,35]$ are shown), we found that thermal conductivities are 150 and $154 \mathrm{~mW} \mathrm{~cm}{ }^{-1} \mathrm{~K}^{-1}$ for $\mathrm{Mg}_{45} \mathrm{Si}_{55}$ and $\mathrm{Mg}_{46} \mathrm{Si}_{54}+0.5 \mathrm{wt} . \% \mathrm{Cu}$, respectively. Note that the smaller value of the specific heat capacity of $\mathrm{Mg}_{45} \mathrm{Si}_{55}$ compared to that of $\mathrm{Mg}_{46} \mathrm{Si}_{54}+0.5 \mathrm{wt} \% \mathrm{Cu}$ (Table 3) can be explained by the lower Si content (Table 1).

The total thermal conductivity of electrically conductive materials contains two contributions, from the lattice, $\kappa_{l a t}$, and free (mobile) charge carriers, $\kappa_{c a t}$, and $\kappa_{t o t}=\kappa_{l a t}+\kappa_{c a t}$. If the carrier concentration is $\geq 5 \times 10^{19} \mathrm{~cm}^{-3}$, the contribution from $\kappa_{\text {lat }}$ and $\kappa_{\text {cat }}$ can be comparable [29]. Both $\mathrm{Mg}_{45} \mathrm{Si}_{55}$ and $\mathrm{Mg}_{46} \mathrm{Si}_{54}+0.5$ wt.\% $\mathrm{Cu}$ contain " $\mathrm{Mg}_{2} \mathrm{Si}$ " and "Si" phases (Table 1), which should affect thermal conductivity differently: according to literature, at $300 \mathrm{~K}$, the thermal conductivity of $\mathrm{Si}$ is $\sim 1500 \mathrm{~mW} \mathrm{~cm} \mathrm{~K}^{-1}$ [35,36]; the thermal conductivity of $\mathrm{Mg}_{2} \mathrm{Si}$ is significantly smaller, between 90 and $100 \mathrm{~mW} \mathrm{~cm}^{-1} \mathrm{~K}^{-1}[6,7,31,32]$. Large values of $\kappa_{\text {tot }}$ show that lattice thermal conductivity in " $\mathrm{Mg}_{2} \mathrm{Si}$ " and "Si" phases prevails, which agrees with the expected small contribution to the total thermal conductivity from carriers (see data for carrier concentration in Table 1 and discussion in Section $C$ ). Heat transfer in the materials studied here is determined by phonon propagation through " $\mathrm{Mg}_{2} \mathrm{Si}$ " and "Si" phases; the total thermal conductivity of the materials is limited by the " $\mathrm{Mg}_{2} \mathrm{Si}$ " phase with lower thermal conductivity. 


\section{Conclusions}

${ }^{29} \mathrm{Si}$ NMR shows that solidification of the alloy with the initial nominal composition of $\mathrm{Mg}_{45} \mathrm{Si}_{55}$ results in formation of " $\mathrm{Mg}_{2} \mathrm{Si}$ " and "Si", i.e., the alloy contains two major phases. XRD patterns of $\mathrm{Mg}_{45} \mathrm{Si}_{55}$ confirm the presence of two phases; calculated lattice parameters are close to those for $\mathrm{Mg}_{2} \mathrm{Si}$ and $\mathrm{Si}$ reported in literature. ${ }^{29} \mathrm{Si}$ NMR spin-lattice relaxation of both major phases in $\mathrm{Mg}_{45} \mathrm{Si}_{55}$ can be fit by at least two components showing that both phases are electronically inhomogeneous, which can be explained by spatial variation of the $\mathrm{Mg}$ :Si ratio in " $\mathrm{Mg}_{2} \mathrm{Si}$ " and by inhomogeneous distribution of dopant(s) in "Si”. Measurements of ${ }^{29}$ Si NMR spin-lattice relaxation time and literature data allow us to estimate the mobile carrier concentrations in "Mg $2 \mathrm{Si}$ " and "Si" phases, which vary between $\sim 6 \times 10^{18}$ and $9 \times 10^{19} \mathrm{~cm}^{-3}$. Similar ${ }^{29} \mathrm{Si}$ NMR spectra and spin-lattice relaxation times are obtained for $\mathrm{Mg}_{46} \mathrm{Si}_{54}+0.5$ wt. $\% \mathrm{Cu}$, which demonstrates insignificant effect of $\mathrm{Cu}$ on local chemical bonding and carrier concentration in both phases. Electron microscopy also shows that both alloys contain two phases. The Seebeck effect of both $\mathrm{Mg}_{45} \mathrm{Si}_{55}$ and $\mathrm{Mg}_{46} \mathrm{Si}_{56}+0.5$ wt.\% Cu shows $p$-type of conductivity; the values of the Seebeck coefficients at $300 \mathrm{~K}$ are similar and determined mostly by the "Si" phase. Heat transfer is determined mostly by phonon propagation through the chemically inhomogeneous material where the total thermal conductivity is limited by that of the " $\mathrm{Mg}_{2} \mathrm{Si}^{\prime}$ " phase with lower thermal conductivity compared to that of "Si". Our study show that XRD, electron microscopy, and NMR are complimentary methods, which allow us to better understand properties of multiphase materials and to use the knowledge obtained for design of novel complex materials. Each phase in alloys studied here produces different contributions to the Seebeck effect and thermal conductivity. The "Si" phase is the primary contributor to the systems Seebeck coefficient while the thermal 
conductivity is limited by the " $\mathrm{Mg}_{2} \mathrm{Si}$ " phase. This opens a pathway to create multiphase materials where each phase can be used to achieve desired properties.

\section{Acknowledgements}

This work was supported by the U.S. Department of Energy, Office of Basic Energy Sciences, Division of Materials Sciences and Engineering. The research was performed at the Ames Laboratory, which is operated for the U.S. Department of Energy by Iowa State University under Contract No DE-AC02-07CH11358.

\section{References}

[1] O. Madelung. Semiconductors: Data handbook. ( $3^{\text {rd }}$ ed. Springer, 2004).

[2] Y. Nishio and T. Hirano, Jpn. J. Appl. Phys. 36 (1997) 170.

[3] S.V. Faleev and F. Leonard, Phys. Rev. B 77 (2008) 214304.

[4] N. Nephytou, X. Zianni, H. Kosina, S. Frabboni, B. Lorenzi, and D. Narducci. Nanotechnology 24 (2013) 205402.

[5] http://pveducation.org/pvcdrom/materials/Mg2Si (accessed April 2014).

[6] J. Tani and H. Kido, Physica B 364 (2005) 218.

[7] M. Akasaka, T. Iida, A. Matsumoto, K. Yamanaka, Y. Takanashi, T. Imai, and N. Hamada, J. Appl. Phys. 104 (2008) 013703.

[8] S. Fiameni, S. Battiston S. Boldrini, A. Famengo, F. Agresti, S. Barison, and M. Fabrizio, J. Solid State Chem. 193 (2012) 142.

[9] D. Cederkrantz, N. Farahi, K.A. Borup, B.B. Iversen, M. Nygren, and A.E.C. Palmqvist. J. Appl. Phys. 111 (2012) 023701. 
[10] T. Yi, S. Chen, S. Li, H. Yang, S. Bux, Z. Bian, N. A. Katcho, A. Shakouri, N. Mingo, J.P. Fleurial, N.D. Browning, and S.M. Kauzlarich, J. Mater. Chem. 22 (2012) 24805.

[11] ASM International 2014: http://www1.asminternational.org.

[12] P. Villars and K. Cenzual, Pearson's Crystal Data: Crystal Structure Database for Inorganic Compounds (on CD-ROM), Release 2012/13, ASM International, Materials Park, Ohio, USA.

[13] Y. Noda, H. Kon, Y. Furukawa, N. Otsuka, I.A. Nishida, and K. Masumoto. Mater. Trans. (JIM) 1992, 33-845

[14] C. Guéneau and C. Servant. J. Appl. Crystallogr. 28 (1995) 707.

[15] F. Weitzer, K. Remschnig, J.C. Schuster, and P. Rogl. J. Mater. Res. 5 (1990) 2152.

[16] R. J. Hill, and C. J. Howard. J. Appl. Cryst. 20 (1987) 467.

[17] E.M. Levin, S.L. Bud'ko, and K. Schmidt-Rohr. Adv. Funct. Mater. 22 (2012) 2766.

[18] R. Elliot. Eutectic solidification. International Metals Review 22 (1997) 161.

[19] E. Ratai, M.P. Augustine, and S.M. Kauzlarich, J. Phys. Chem. B 107 (2003) 12573.

[20] F. Dogan, C. Joyce, and J.T. Vaughey, J. Electrochem. Soc. 160 (2013) A312.

[21] N.W. Ashcroft and N.D. Mermin, Solid State Physics (Brooks/Cole, Cengage Learning, Belmont, CA, USA, 1976).

[22] A.Y. Shik, Electronic properties of inhomohgeneous semiconductors. (Gordon and Breach Publishers, 1995).

[23] E.M. Levin, B.A. Cook, K. Ahn, M.G. Kanatzidis, and K. Schmidt-Rohr. Phys. Rev. B 80 (2009) 115211.

[24] E.M. Levin, J.P. Heremans, M.G. Kanatzidis, and K. Schmidt-Rohr. Phys. Rev. B 88 (2013) 115211. 
[25] R.G. Shulman and B.J. Wyluda, Phys. Rev. 103 (1956) 1127.

[26] A. Abragam. The Principles of Nuclear Magnetism. Oxford, Clarendon Press, 1961, 599 p.

[27] G. C. Brown and D. F. Holcomb, Phys. Rev. B 10 (1974) 3394.

[28] D.R. Cousens, R. Rasch, and C.G. Ryan. Micron 28 (1997) 231.

[29] G.J. Snyder and E. S. Toberer. Nature Mater. 7 (2008) 105.

[30] www.virginiasemi.com (accessed April 2014).

[31] R.J. LaBotz and D.R. Mason. J. Electrochem Soc. 110 (1963) 121.

[32] J.J. Martin. J. Phys. Chem. Solids 33 (1972) 1139.

[33] Thermal conductivities: theory, properties, and applications. By T.M. Tritt, ed. (Springer, 2004).

[34] http://www.gelest.com/goods/pdf/metalOrganicCatalog/12.pdf

[35] http://periodictable.com/Elements/014/data.html

[36] C.J. Glassbrenner and G.A. Slack. Phys. Rev. 134 (1964) A1058. 

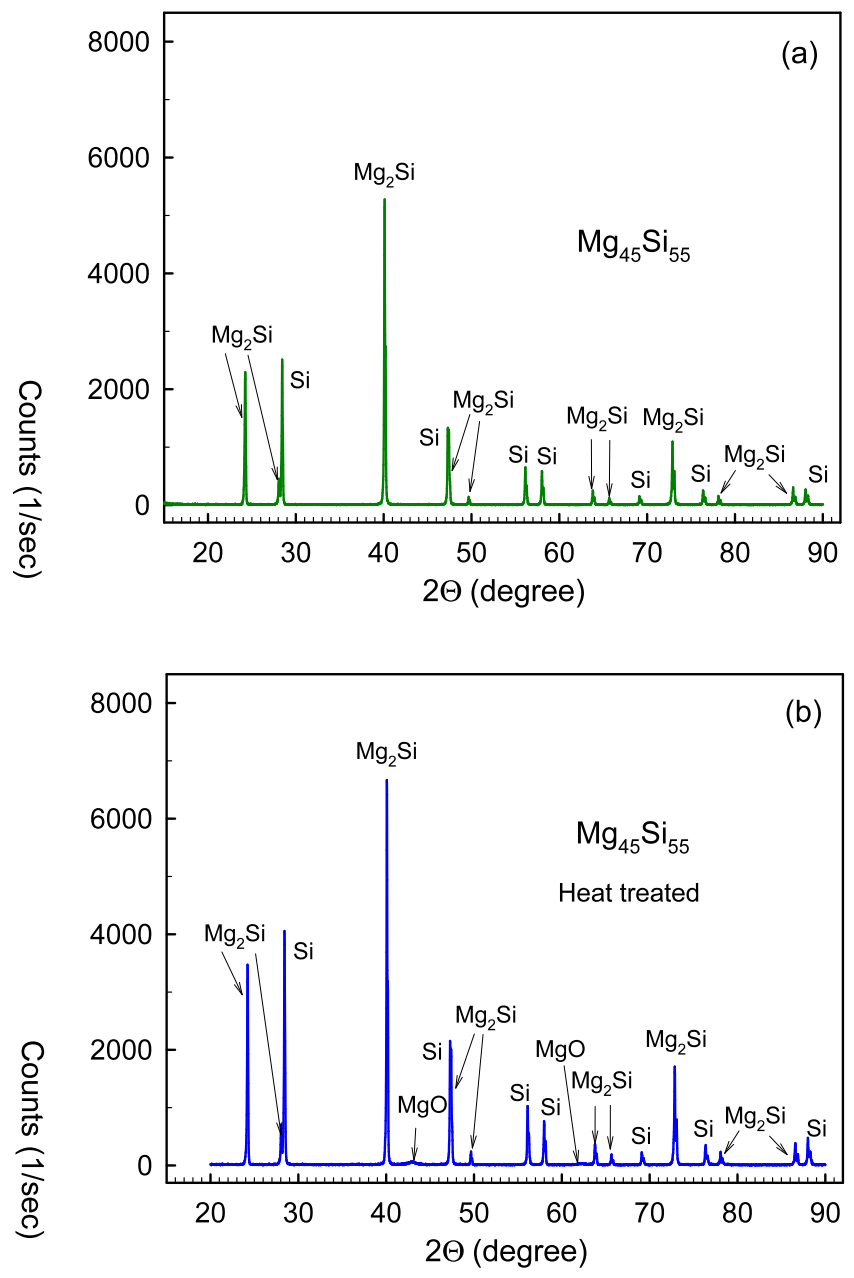

Fig. 1. X-ray diffraction patterns of (a) $\mathrm{Mg}_{45} \mathrm{Si}_{55}$ as solidified and (b) after heat treatment at $780 \mathrm{~K}$ for $2 \mathrm{~h}$ in He environment. 

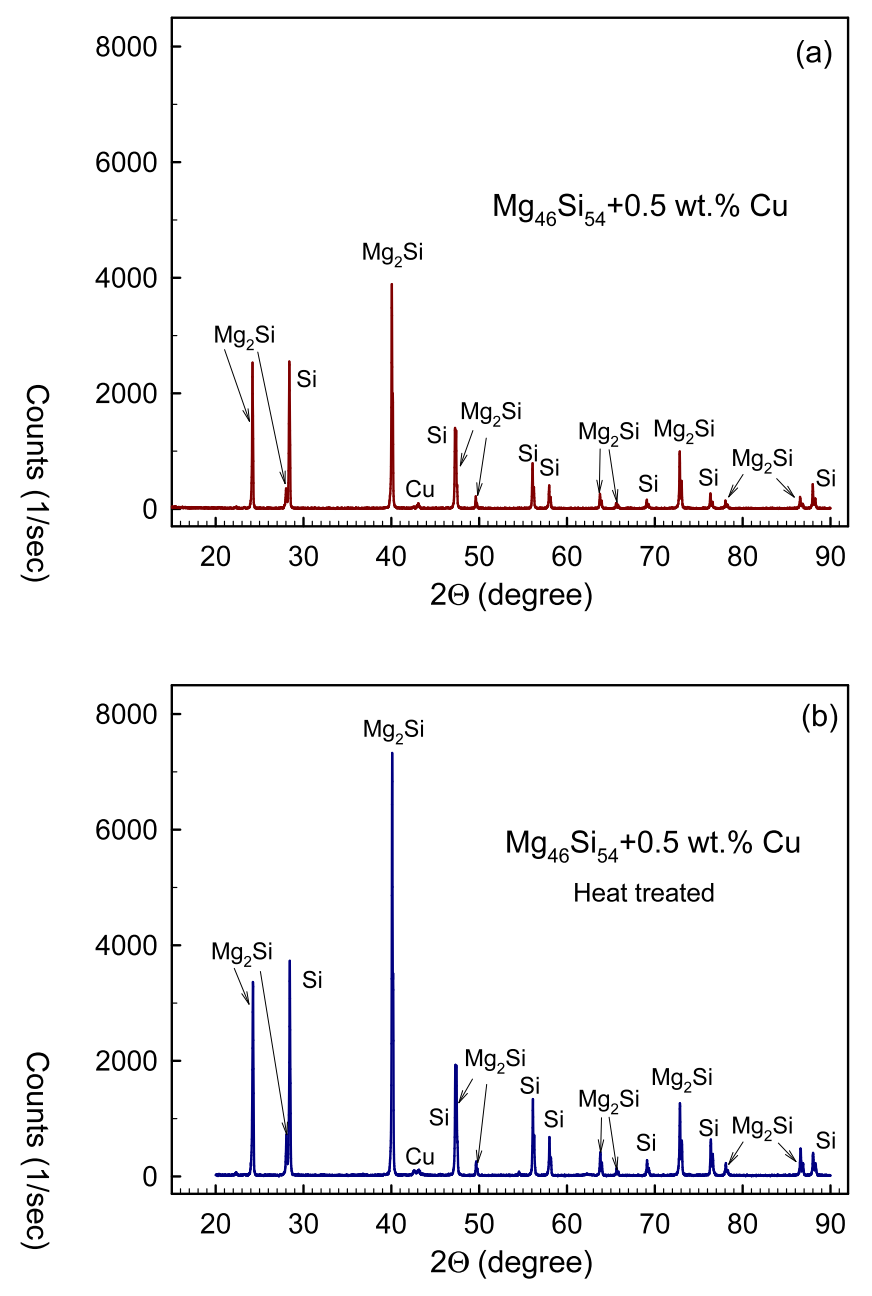

Fig. 2. X-ray diffraction patterns of (a) $\mathrm{Mg}_{44} \mathrm{Si}_{56}+0.5 \mathrm{wt} . \% \mathrm{Cu}$ as solidified and (b) after heat treatment at $780 \mathrm{~K}$ for $2 \mathrm{~h}$ in He environment. 

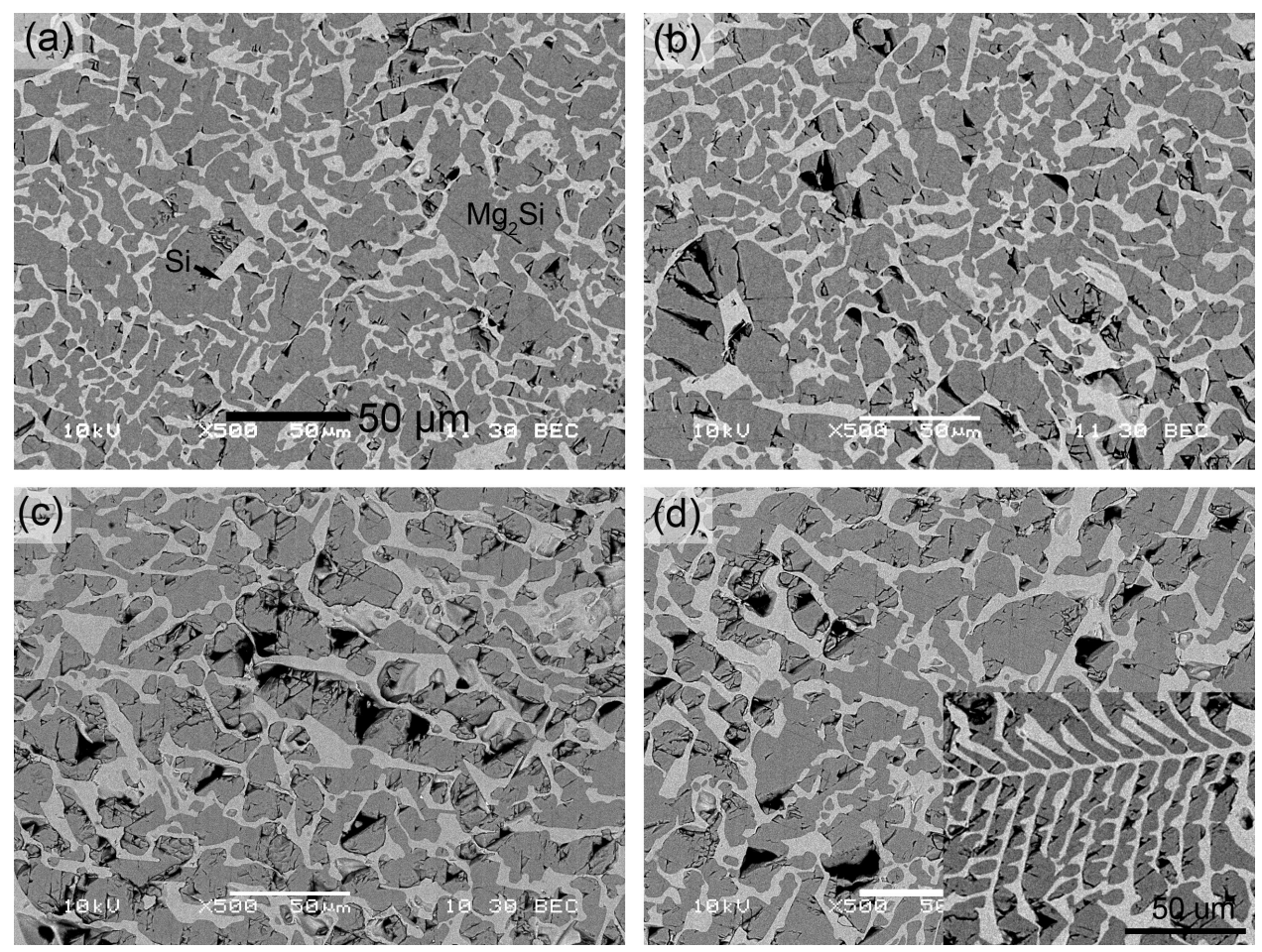

Fig. 3. Backscattered electron images of $\mathrm{Mg}_{44} \mathrm{Si}_{55}$ from the transverse views of regions (a) near the top edge, (b) in the top center, (c) near the bottom edge, and (d) at the bottom center regions in a directionally solidified $\mathrm{Mg}_{45} \mathrm{Si}_{55}$ alloy. $\mathrm{Mg}_{2} \mathrm{Si}$ appears darker than $\mathrm{Si}$. Inset in (d) is a fishbone structure of Si. The darkest regions are pits caused by Si pieces falling out of the specimens during polishing. Note that images indicate a refinement close to the surface. 


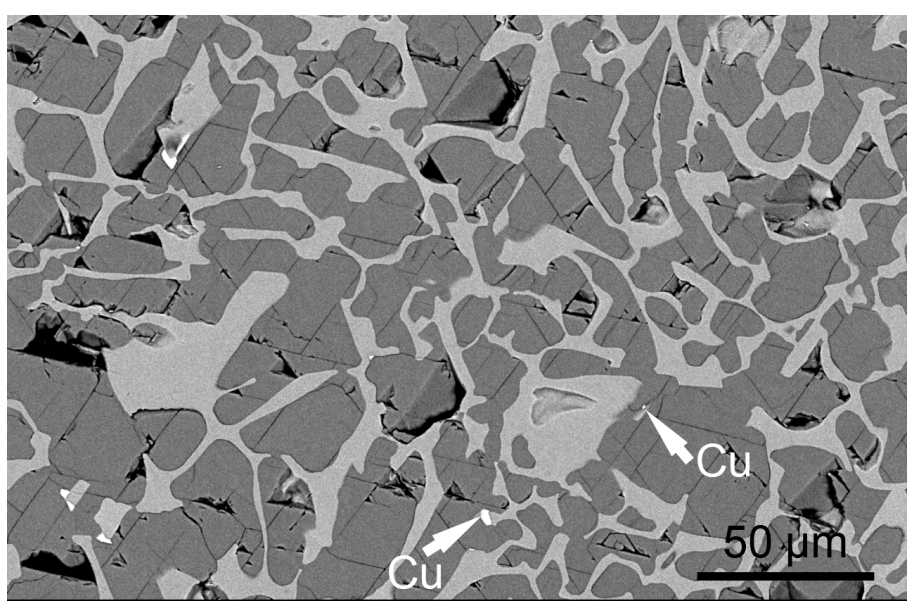

Fig. 4. Backscattered electron images of $\mathrm{Mg}_{44} \mathrm{Si}_{55}+0.5 \mathrm{wt} . \% \mathrm{Cu}$ from the transverse view of the ingot bottom. Some $\mathrm{Cu}$ precipitates are marked with arrows. 

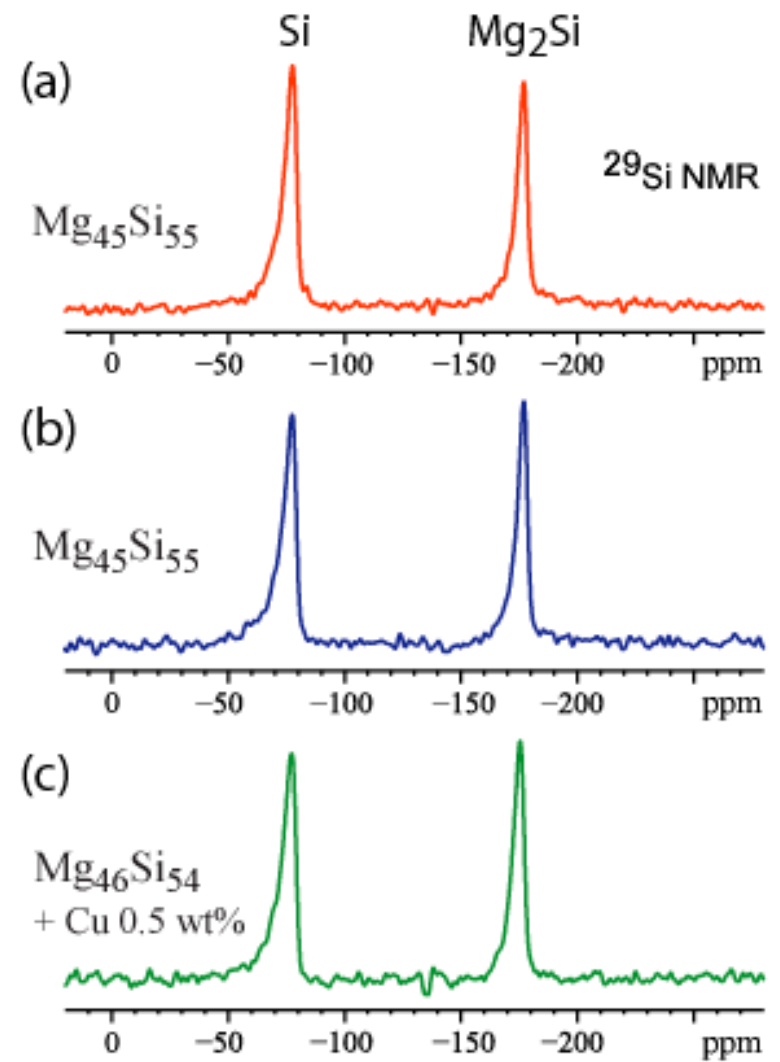

Fig. 5. ${ }^{29} \mathrm{Si}$ NMR spectra with magic-angle spinning of (a) and (b) $\mathrm{Mg}_{45} \mathrm{Si}_{55}$ (samples \#1 and $\# 2$, respectively), and (c) of $\mathrm{Mg}_{46} \mathrm{Si}_{54}+0.5 \mathrm{wt} . \% \mathrm{Cu}$. 


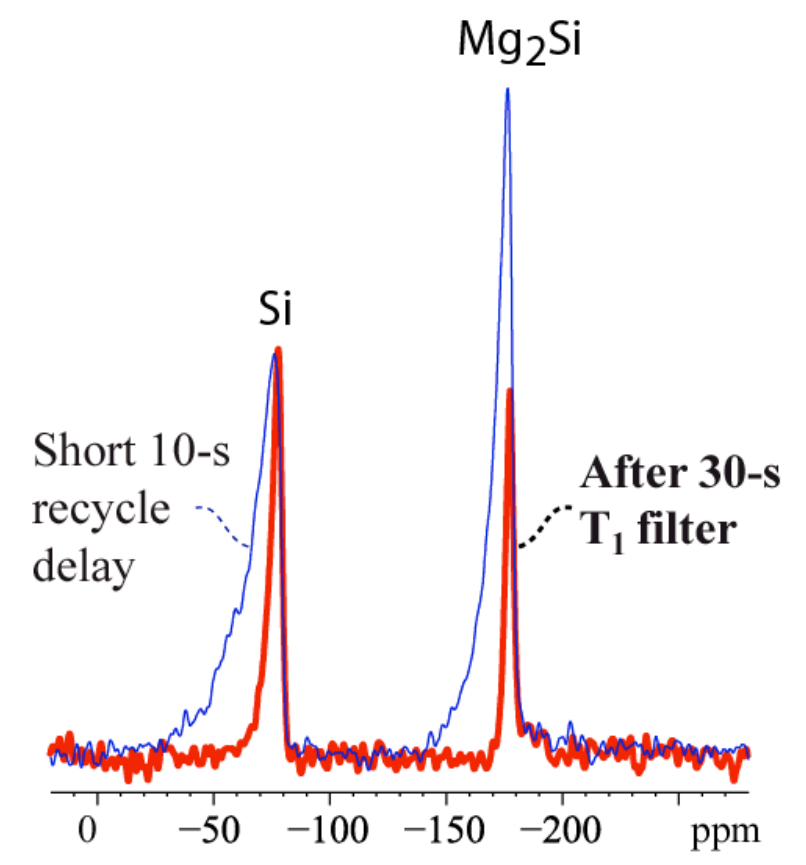

Fig. 6. Selective ${ }^{29} \mathrm{Si}$ MAS NMR spectra of $\mathrm{Mg}_{45} \mathrm{Si}_{55}$ (sample \#1). Thin line: Spectrum after short recycle delay of $10 \mathrm{~s}$, dominated by signals of components with short $T_{1}$ relaxation times. Thick line: Spectrum after 30-s $T_{1}$ filter, with 500-s recycle delay. The spectra were scaled to equal height of the left peak. 

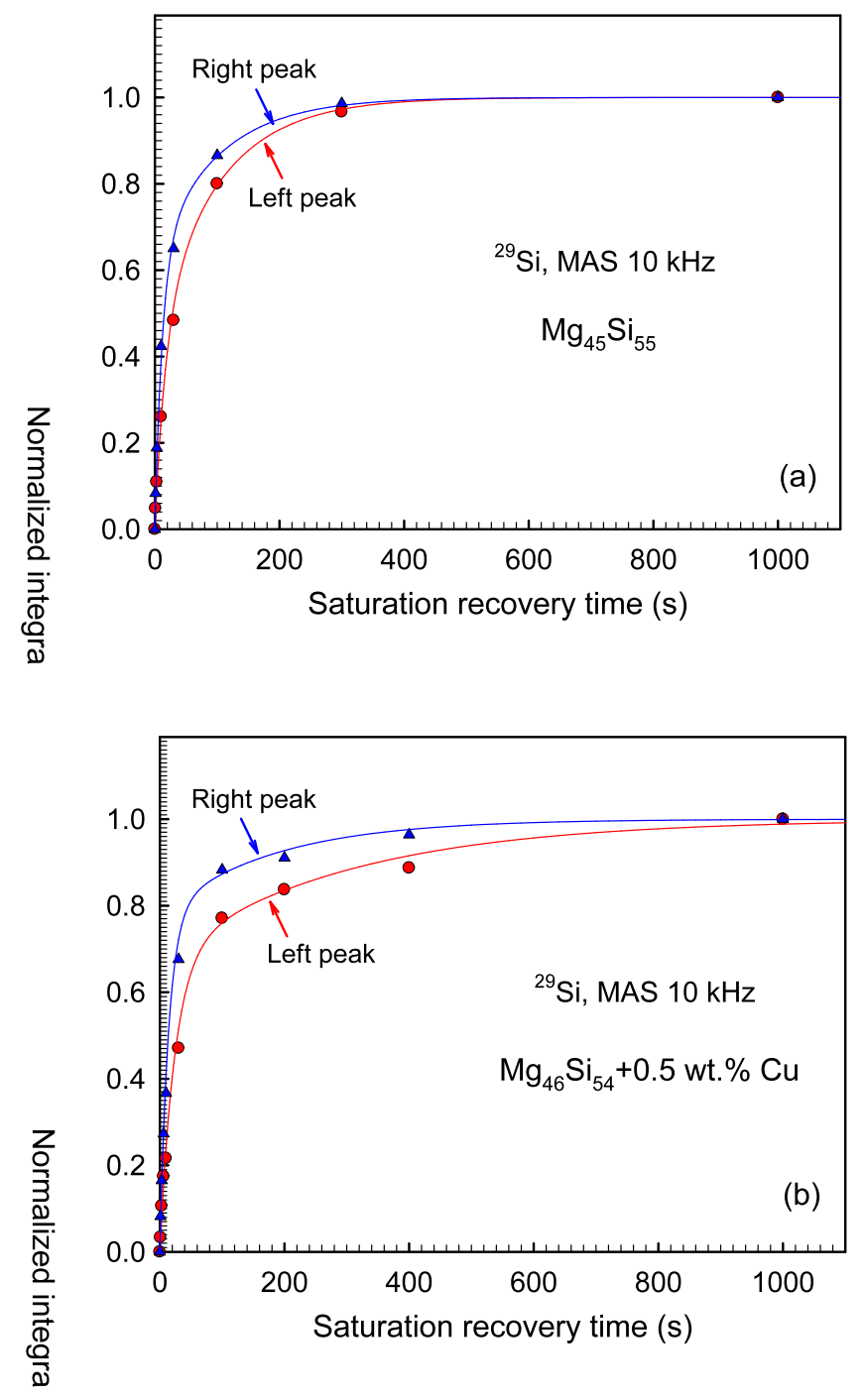

Fig. 7. ${ }^{29} \mathrm{Si}$ NMR normalized integral vs. saturation recovery time for (a) $\mathrm{Mg}_{45} \mathrm{Si}_{55}$ (sample \#1) and (b) $\mathrm{Mg}_{46} \mathrm{Si}_{54}+0.5 \mathrm{wt} . \% \mathrm{Cu}$. 

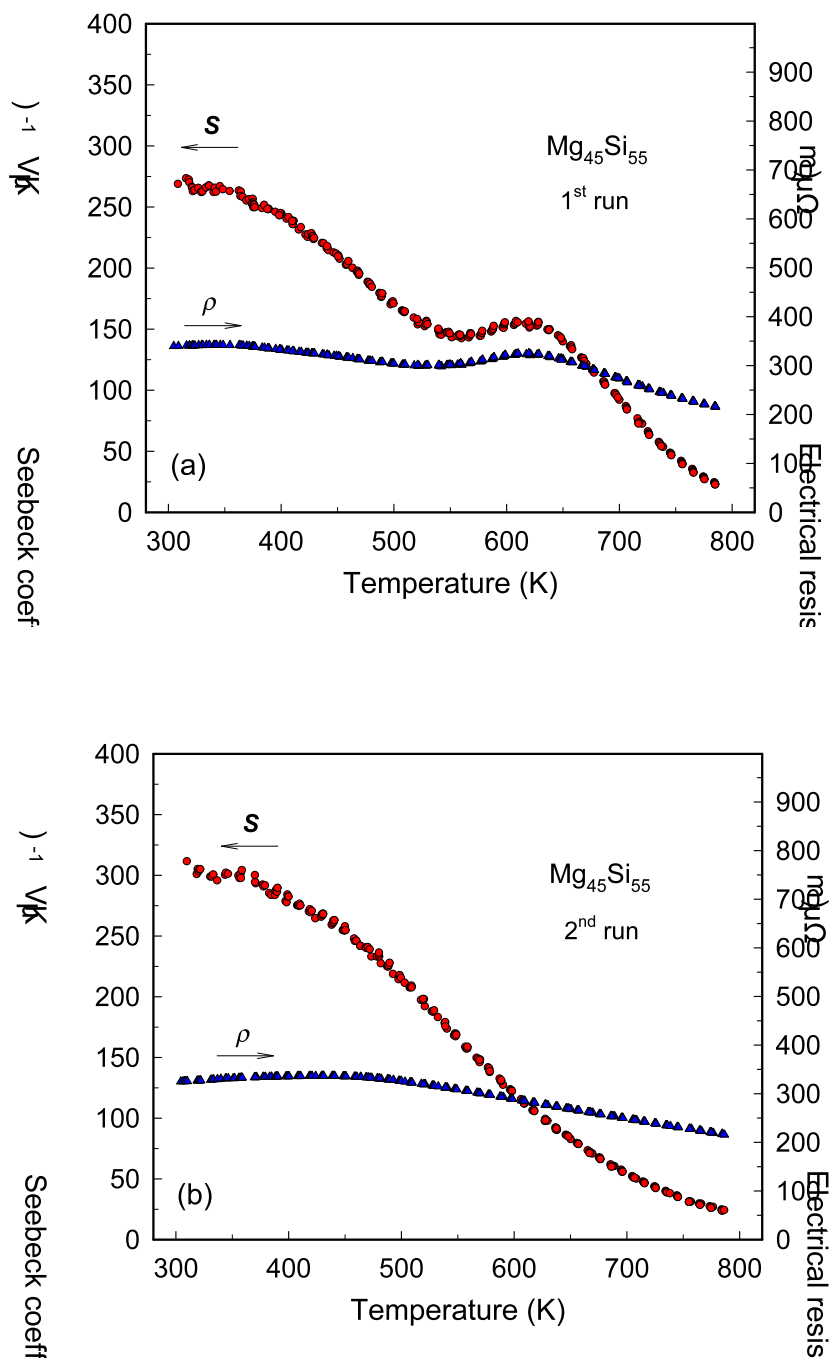

Fig. 8. Temperature dependencies of the absolute Seebeck coefficient and electrical resistivity of $\mathrm{Mg}_{45} \mathrm{Si}_{55}$ for the (a) first and (b) second run. Both dependencies during the following third run are similar to those observed for the second one. 

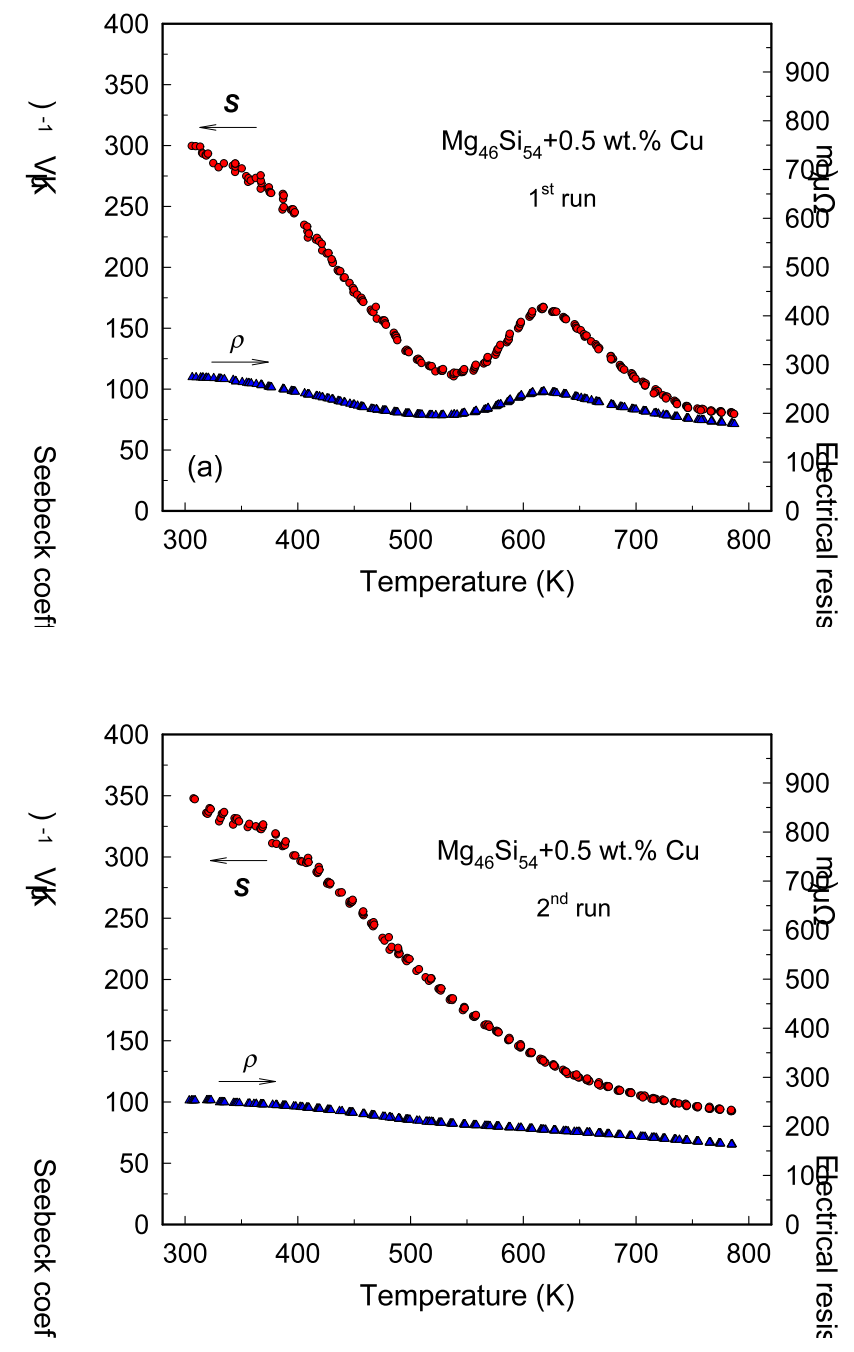

Fig. 9. Temperature dependencies of the Seebeck coefficient and electrical resistivity of $\mathrm{Mg}_{46} \mathrm{Si}_{54}+0.5$ wt. $\% \mathrm{Cu}$ for the (a) first and (b) second run. Both dependencies during the following third run are similar to those observed for the second one. 


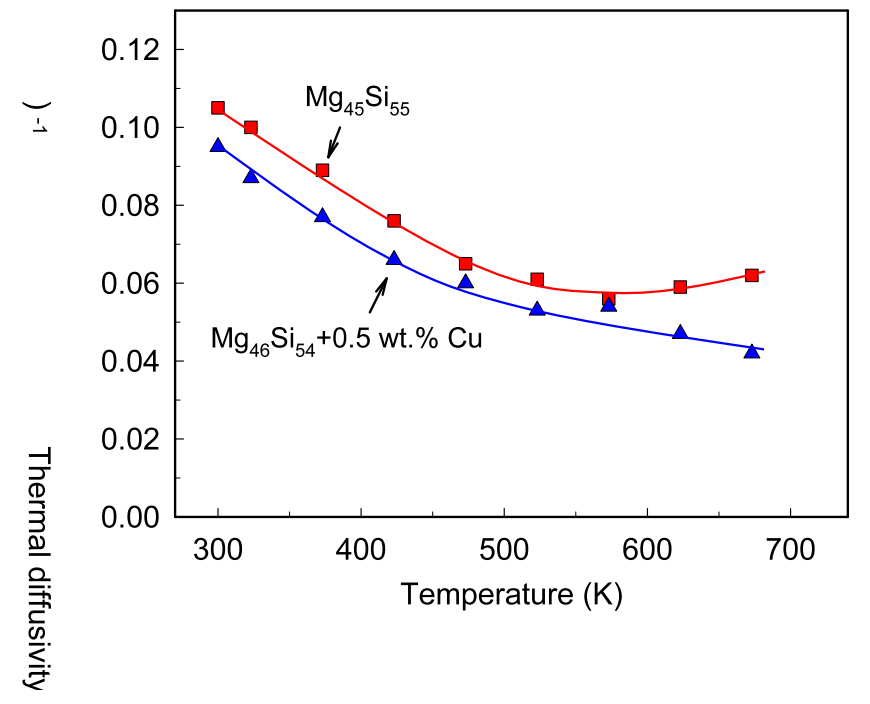

Fig. 10. Temperature dependencies of the thermal diffusivity of $\mathrm{Mg}_{45} \mathrm{Si}_{55}$ and $\mathrm{Mg}_{46} \mathrm{Si}_{54}+0.5$ wt.\% $\mathrm{Cu}$. 
Table 1. Phase content and lattice parameters of $\mathrm{Mg}_{45} \mathrm{Si}_{55}$ and $\mathrm{Mg}_{46} \mathrm{Si}_{54}+0.5$ wt.\% Cu alloys as solidified and heat treated ${ }^{[\mathrm{a}]}$ (data for two $\mathrm{Mg}_{45} \mathrm{Si}_{55}$ samples are shown) determined by XRD and ${ }^{29} \mathrm{Si}$ NMR.

\begin{tabular}{|c|c|c|c|c|c|c|}
\hline \multirow[b]{3}{*}{ Composition } & \multicolumn{4}{|c|}{ From XRD } & \multicolumn{2}{|c|}{ From ${ }^{29} \mathrm{Si}$ NMR } \\
\hline & \multicolumn{2}{|c|}{ "Mg $\mathrm{Si}$} & \multicolumn{2}{|c|}{ "Si" } & \multirow{2}{*}{$\begin{array}{l}\text { "Mg } \mathrm{Mg}_{2} \mathrm{Si} \\
\text { content }\end{array}$} & \multirow{2}{*}{$\begin{array}{l}\text { "Si" } \\
\text { conten }\end{array}$} \\
\hline & Content & $\begin{array}{l}\text { Lattice } \\
\text { param. }(\AA)\end{array}$ & Content & $\begin{array}{l}\text { Lattice } \\
\text { param. }(\AA)\end{array}$ & & \\
\hline $\mathrm{Mg}_{45} \mathrm{Si}_{55}($ sample \#1) & $72 \%$ & 6.3503 & $28 \%$ & 5.42927 & $70 \%$ & $30 \%$ \\
\hline $\mathrm{Mg}_{45} \mathrm{Si}_{55}($ sample \#2) & $71 \%$ & 6.3510 & $29 \%$ & 5.42927 & $70 \%$ & $30 \%$ \\
\hline $\mathrm{Mg}_{45} \mathrm{Si}_{55}$, ht (sample \#1) & $65 \%$ & 6.3522 & $35 \%$ & 5.42876 & - & - \\
\hline $\mathrm{Mg}_{46} \mathrm{Si}_{54}+0.5$ wt. $\% \mathrm{Cu}^{[\mathrm{cc}]}$ & $63 \%$ & 6.3514 & $35 \%$ & 5.42916 & $69 \%$ & $31 \%$ \\
\hline $\mathrm{Mg}_{46} \mathrm{Si}_{54}+0.5$ wt. $\% \mathrm{Cu}, \mathrm{ht}^{[\mathrm{cc}]}$ & $68 \%$ & 6.3523 & $30 \%$ & 5.42946 & - & - \\
\hline
\end{tabular}

${ }^{\text {[a] }}$ Heat treated (ht) at $780 \mathrm{~K}$ for $2 \mathrm{~h}$ in He environment.

${ }^{[b]}$ Lattice parameters (literature data [1]): $\mathrm{Si}, a=5.431 \AA, \mathrm{Mg}_{2} \mathrm{Si}, a=6.338 \AA$.

${ }^{[c]}$ A third phase of $\mathrm{Cu}$ in small concentration $(\leq 2 \%)$ also was detected by XRD. 
Table 2. ${ }^{29} \mathrm{Si}$ NMR spin-lattice relaxation, $T_{1}$, for " $\mathrm{Mg}_{2} \mathrm{Si}$ " phase and "Si" phases, and free carrier concentration in electronically inhomogeneous $\mathrm{Mg}_{45} \mathrm{Si}_{55}$ and $\mathrm{Mg}_{46} \mathrm{Si}_{54}+0.5$ wt.\% Cu alloys.

\begin{tabular}{|c|c|c|c|}
\hline Composition & $\begin{array}{c}\text { "Mg } \mathrm{Mg}_{2} \mathrm{Si} " \\
\text { Peak at }-177 \text { ppm }\end{array}$ & $\begin{array}{c}\text { "Si"' } \\
\text { Peak at }-80 \text { ppm }\end{array}$ & $\begin{array}{l}\text { Carrier concentration } \\
\left(\mathrm{cm}^{-3}\right)\end{array}$ \\
\hline \multirow[t]{4}{*}{$\mathrm{Mg}_{45} \mathrm{Si}_{55}($ sample \#1) } & - & 17 & $6 \times 10^{19}$ \\
\hline & - & 100 & $\sim 10^{19}$ \\
\hline & 12 & - & $9 \times 10^{19}$ \\
\hline & 100 & - & $\sim 10^{19}$ \\
\hline \multirow[t]{4}{*}{$\mathrm{Mg}_{45} \mathrm{Si}_{55}$ (sample \#2) } & - & 15 & $7 \times 10^{19}$ \\
\hline & - & 90 & $\sim 10^{19}$ \\
\hline & 16 & - & $7 \times 10^{19}$ \\
\hline & 150 & - & $7 \times 10^{18}$ \\
\hline \multirow[t]{4}{*}{$\mathrm{Mg}_{46} \mathrm{Si}_{54}+0.5$ wt. $\% \mathrm{Cu}$} & - & 24 & $4 \times 10^{19}$ \\
\hline & - & 300 & $4 \times 10^{18}$ \\
\hline & 16 & - & $7 \times 10^{19}$ \\
\hline & 180 & - & $6 \times 10^{18}$ \\
\hline
\end{tabular}


Table 3. Mass density, specific heat capacity, thermal diffusivity, and thermal conductivity of $\mathrm{Mg}_{45} \mathrm{Si}_{55}$ and $\mathrm{Mg}_{46} \mathrm{Si}_{54}+0.5 \mathrm{wt} . \% \mathrm{Cu}$ at $300 \mathrm{~K}$. Data for $\mathrm{Mg}_{2} \mathrm{Si}$ and $\mathrm{Si}$ are shown for comparison.

\begin{tabular}{lcccc}
\hline \hline Composition & $\begin{array}{l}\text { Mass } \\
\text { density } \\
\left(\mathrm{g} \mathrm{cm}^{-3}\right)\end{array}$ & $\begin{array}{c}\text { Specific heat } \\
\text { capacity } \\
\left(\mathrm{J} \mathrm{g}^{-1} \mathrm{~K}^{-1}\right)\end{array}$ & $\begin{array}{l}\text { Thermal } \\
\text { diffusivity } \\
\left(\mathrm{cm}^{2} \mathrm{~s}^{-1}\right)\end{array}$ & $\begin{array}{l}\text { Thermal } \\
\text { conductivity } \\
\left(\mathrm{mW} \mathrm{cm}^{-1} \mathrm{~K}^{-1}\right)\end{array}$ \\
\hline $\mathrm{Mg}_{45} \mathrm{Si}_{55}$ & 2.07 & 0.70 & 0.105 & 150 \\
$\mathrm{Mg}_{46} \mathrm{Si}_{54}+0.5 \mathrm{wt.} \% \mathrm{Cu}$ & 2.09 & 0.78 & 0.095 & 155 \\
$\mathrm{Mg}_{2} \mathrm{Si}$ & $1.88[1]$ & $0.87[5,34]$ & 0.06 & $90-100[6,7,31,32]$ \\
$\mathrm{Si}$ & $2.33[1,35]$ & $0.71[35]$ & $0.86[30]$ & $1500[35,36]$ \\
\hline \hline
\end{tabular}

